Appl. Phys. A 58, 371-376 (1994)

\title{
Thermal Stability of Mo/Si Multilayer Soft-X-Ray Mirrors Fabricated by Electron-Beam Evaporation
}

\author{
H.-J. Stock ${ }^{1}$, U. Kleineberg ${ }^{1}$, B. Heidemann ${ }^{1}$, K. Hilgers ${ }^{1}$, A. Kloidt ${ }^{1}$, B. Schmiedeskamp ${ }^{\text {, }}$ U. Heinzmann ${ }^{1}$, \\ M. Krumrey ${ }^{2, \star}$, P. Müller ${ }^{2}$, F. Scholze ${ }^{2}$ \\ 1 Universität Bielefeld, Fakultät für Physik, D-33501 Bielefeld, Germany (Fax: $+49-521 / 1066001$ ) \\ 2 Physikalisch-Technische Bundesanstalt, Institut Berlin, D-10587 Berlin, Germany
}

Received in revised form 12 November 1993/Accepted 7 December 1993

\begin{abstract}
Mo/Si multilayers are fabricated by electronbeam evaporation in UHV at different temperatures $\left(30^{\circ} \mathrm{C}\right.$, $150^{\circ} \mathrm{C}, 200^{\circ} \mathrm{C}$ ) during deposition. After completion their thermal stability is tested by baking them at temperatures $\left(T_{\text {bak }}\right.$ ) between $200^{\circ} \mathrm{C}$ and $800^{\circ} \mathrm{C}$ in steps of $50^{\circ} \mathrm{C}$ or $100^{\circ} \mathrm{C}$. After each baking step the multilayers are characterized by small angle $\mathrm{Cu}_{K_{\alpha}}$-X-ray diffraction. Additionally, the normal incidence soft-X-ray reffectivity for wavelengths between $11 \mathrm{~nm}$ and $19 \mathrm{~nm}$ is determined after baking at $500^{\circ} \mathrm{C}$. Furthermore, the layer structure of the multilayers is investigated by means of Rutherford Backscattering Spectroscopy (RBS) and sputter/Auger Electron Spectroscopy (AES) technique. While the reflectivity turns out to be highest for a deposition temperature of $150^{\circ} \mathrm{C}$, the thermal stability of the multilayer increases with deposition temperature. The multilayer deposited at $200^{\circ} \mathrm{C}$ stands even a $20 \mathrm{~min} 500^{\circ} \mathrm{C}$ baking without considerable changes in the reflectivity behaviour.
\end{abstract}

PACS: $68.55,68.65,78.65$

In the wavelength range between $13 \mathrm{~nm}$ and $30 \mathrm{~nm}$ the combination of $\mathrm{Mo}$ and $\mathrm{Si}$ is most widely used for normalincidence multilayer mirrors. Reflectivities around $60 \%$ have been achieved with both sputtering [1] and $e^{-}$-beam evaporation in combination with thermal treatments during deposition [2,3]. Besides a high value for the reflectivity, the stability of the multilayer stack is also an important property, since applications include for example synchrotron radiation optics, where the multilayer can be heated to a few hundred degrees Celsius [4]. The long-term stability is also important for a number of applications.

The thermal stability of Mo/Si multilayers has been studied earlier in several works [5-11] but in all of them the multilayers are fabricated by sputtering. In [12] it is shown that thermal treatment during $e^{-}$-beam deposition can considerably enhance the reflectivity of $\mathrm{Mo} / \mathrm{Si}$ multilayer

\footnotetext{
* Present address: European Synchrotron Radiation Facility, F-38043 Grenoble, France
}

mirrors with a double layer spacing of about $7.5 \mathrm{~nm}$. For a deposition temperature $\left(T_{\text {dep }}\right)$ of $150^{\circ} \mathrm{C}$ the reflectivity is about a factor of two larger than the reflectivity of the $30^{\circ} \mathrm{C}$ and $200^{\circ} \mathrm{C}$ sample $[12,13]$. In other previous works $[14,15]$ the influence of the deposition temperature on the microstructure of $\mathrm{Mo} / \mathrm{Si}$-multilayer systems fabricated by $e^{-}$- beam evaporation was studied. They have shown that $\mathrm{Mo} / \mathrm{Si}$ multilayers have interlayers of a mixture of Mo and $\mathrm{Si}$ at the Mo-Si interfaces and that the thickness of Mo- on- Si interlayers increases with increasing deposition temperature, while the thickness of the Si- on-Mo interlayers keeps constant. In our work the influence of the different microstructure for the multilayers which were deposited at different temperatures on the thermal stability is also investigated.

\section{Experiment}

In this work we study the thermal stability of Mo/Si multilayer mirrors which are $e^{-}$-beam deposited at $30^{\circ} \mathrm{C}, 150^{\circ} \mathrm{C}$ and $200^{\circ} \mathrm{C}$. The multilayers are fabricated in ultra high vacuum with two $e^{-}$-beam evaporation sources, one for Mo and one for $\mathrm{Si}$. The distance between the substrates and the evaporation sources is around $65 \mathrm{~cm}$. The deposition system possesses two quartz oscillators for measurements of deposition rate and layer thickness. The layer thickness is controlled by an in situ reflectivity measurement with $\mathrm{Cu}_{K_{\alpha}}$-radiation $(\lambda=4.47 \mathrm{~nm})$ at an angle of $\alpha=70^{\circ}$ with respect to the surface normal of the substrate. The substrates can be heated with a tungsten filament. $T_{\text {dep }}$ is measured at the substrate holder with a $\mathrm{NiCr} / \mathrm{CuNi}$ thermocouple. The base pressure of the system is around $1 \times 10^{-8} \mathrm{~Pa}$ and typical pressures during deposition are about $1 \times 10^{-6} \mathrm{~Pa}$. The deposition rates are $0.06 \AA / \mathrm{s}$ for Mo and $0.02 \AA / \mathrm{s}$ for Si. As substrates $\mathrm{Si}$ (100) wafers were used. All the results described in this work are obtained for multilayers with 12 double layers and a double layer with a thickness ( $d$-spacing) of about $7.5 \mathrm{~nm}$. The nominal thickness was about $2.5 \mathrm{~nm}$ for Mo and $5 \mathrm{~nm}$ for $\mathrm{Si}$. The samples are baked to temperatures between $200^{\circ} \mathrm{C}$ and $800^{\circ} \mathrm{C}$ in steps of $50^{\circ} \mathrm{C}$ or $100^{\circ} \mathrm{C}$. The baking is done under vacuum $\left(5 \times 10^{-3} \mathrm{~Pa}\right)$ for $20 \mathrm{~min}$ at each 
temperature. The temperature is measured at the substrate holder with a $\mathrm{NiCr} / \mathrm{CuNi}$ thermocouple. After each baking step the samples are characterized by measuring the small angle $\mathrm{X}$-ray reflection with a $\mathrm{Cu}_{K_{\alpha}}$ line source. The material distribution of the as deposited $\mathrm{X}$-ray mirrors fabricated at different temperatures is studied with sputter/AES-depth profiling. Sputtering was performed by means of $600 \mathrm{eV}$ $\mathrm{Xe}$ ions. The depth resolution is $1 \mathrm{~nm}$. Additionally, the baking induced changes in the material distribution of the multilayer deposited at $150^{\circ} \mathrm{C}$ are investigated by means of high-resolution RBS. These measurements were carried out by use of a $\mathrm{He}^{+}$beam provided by a $350 \mathrm{keV}$ ion accelerator. The energy of the backscattered ions is determined using a toroidal electrostatic analyzer. These characterization methods give information about the $d$-spacing, interfacial roughness, formation of interfaces and thickness errors, and thus, especially about the general quality of the stack. In addition, the diffusion processes that have occured during thermal treatments can be observed. Further details about the fabrication and characterization procedures are given in [16]. The normal-incidence reflectivity for soft X-rays is determined in the spectral region of $11-19 \mathrm{~nm}$ using a reflectometer at the electron storage ring BESSY [17].

\section{Results}

\subsection{Sputter/AES-Depth Profiling}

The distribution of the material within the stack for the as deposited mirrors was investigated by sputter/AES-depth profiling. The ratio of intensities $I / I_{\max }$ for Mo and Si versus the sputter depth are given in Fig. 1 for the multilayers deposited at $30^{\circ} \mathrm{C}, 150^{\circ} \mathrm{C}$ and $200^{\circ} \mathrm{C}$. The AES signals of $\mathrm{Si}$ for $30^{\circ} \mathrm{C}$ and $200^{\circ} \mathrm{C}$ deposition temperature show lower oscillations than for $150^{\circ} \mathrm{C}$. The peaks of the AES signals are asymmetric, which is less pronounced for the $30^{\circ} \mathrm{C}$ system than for the stacks of higher deposition temperature. The more symmetric peaks of the layers deposited at $30^{\circ} \mathrm{C}$ indicate similar interfaces for both the Mo- on- $\mathrm{Si}$ and the Si- on- Mo side, the shallow slopes combined with lower $\mathrm{Si}$ oscillations are in agreement with rather rough interfacial

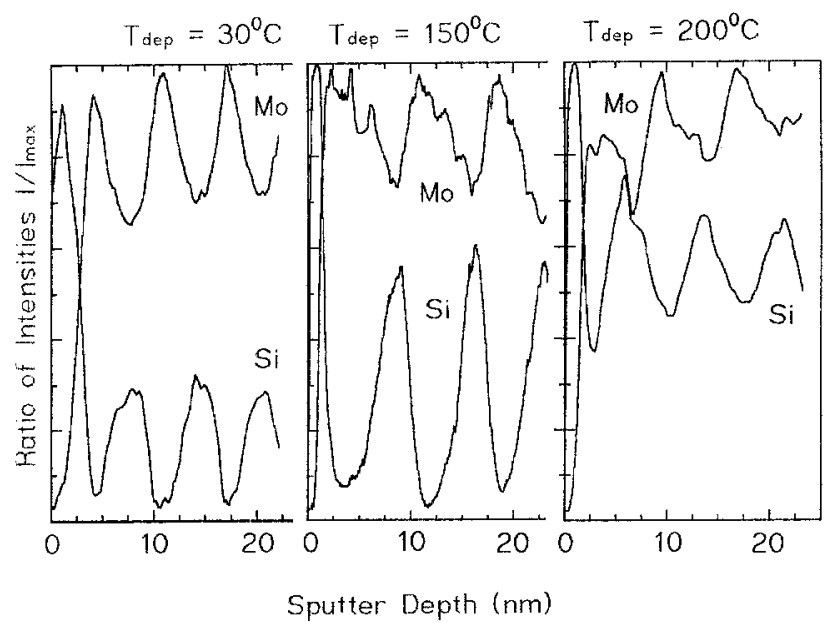

Fig. 1. Mo and Si peak heights in sputter/AES-depth profiles for asdeposited multilayers deposited at different temperatures regions. The asymmetric form especially for the Mo signal of the $150^{\circ} \mathrm{C}$ and $200^{\circ} \mathrm{C}$ stacks indicates sharper interfaces on the Si- on- Mo side than on the Mo- on- Si side, the steps in the slopes can be caused by interface layers. These results are in agreement with $[14,15]$. For the $200^{\circ} \mathrm{C}$ system the Si signal does not drop to values near zero. This can be explained by interdiffusion of $\mathrm{Si}$ and $\mathrm{Mo}$, which leads to layers which are not as well separated as for the $150^{\circ} \mathrm{C}$ stack.

\subsection{Small-Angle X-Ray Scattering}

Figure 2 shows a series of $\mathrm{Cu}_{K_{\alpha}}$ reflectivity curves obtained for a multilayer which is deposited at $150^{\circ} \mathrm{C}$. The reflectivity curve of the as deposited sample was measured up to the fourth Bragg order. The baking procedure does not induce significant changes in the reflectivity behaviour up to temperatures of $400^{\circ} \mathrm{C}$, as can be seen in Fig. 2. After baking to $500^{\circ} \mathrm{C}$ the first-, second- and third-order Bragg maxima are located at larger angles $\Theta$ and the intensity ratio

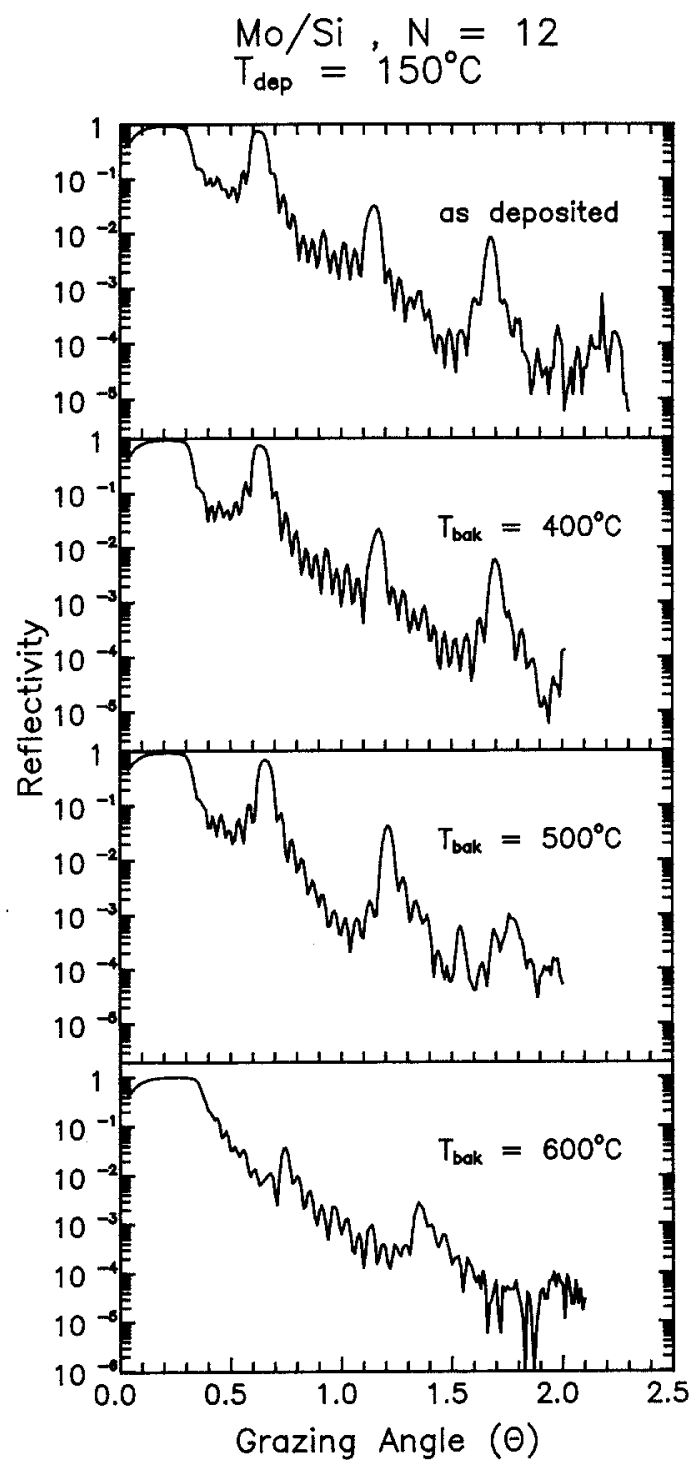

Fig. 2. Small angle $\mathrm{Cu}_{K_{\alpha}} \mathrm{X}$-ray diffraction of the multilayer deposited at $150^{\circ} \mathrm{C}$ directly after completion $\left(30^{\circ} \mathrm{C}\right)$ and after baking at $400^{\circ} \mathrm{C}$, $500^{\circ} \mathrm{C}$ and $600^{\circ} \mathrm{C}$ 
between the second- and third-order Bragg peak has changed considerably. The former finding is due to a change in $d$ spacing [10] while the latter can be explained by a change in the ratio of absorber (Mo) and spacer ( $\mathrm{Si}$ ) thickness [12]. Baking to $600^{\circ} \mathrm{C}$ yields a drastic decrease of the reflectivity of the first-order Bragg peak and a further considerable shift of the Bragg maxima to larger $\Theta$. A pronounced secondorder Bragg peak remains visible; this indicates that the reduction in reflectivity of the first-order Bragg peak is rather due to a thickness reduction of the silicon spacer layer by diffusion than due to a thermally induced roughening of the interfaces, because thermally induced roughening of the interfaces reduces the reflectivity of the higher Bragg orders more than the reflectivity of the lower [7]. This qualitative picture is further supported by a more detailed study of the first- and second-order Bragg maxima-intensities and -positions, which are displayed in Fig. 3. Open circles represent the results of the stack deposited at $150^{\circ} \mathrm{C}$, crosses and open squares those for deposition at room temperature and at $200^{\circ} \mathrm{C}$. The first-order Bragg peak intensity (Fig. 3a) remains almost constant for all samples up to a certain temperature and decreases then drastically with increasing temperature. The breakdown of the reflectivity occurs for our

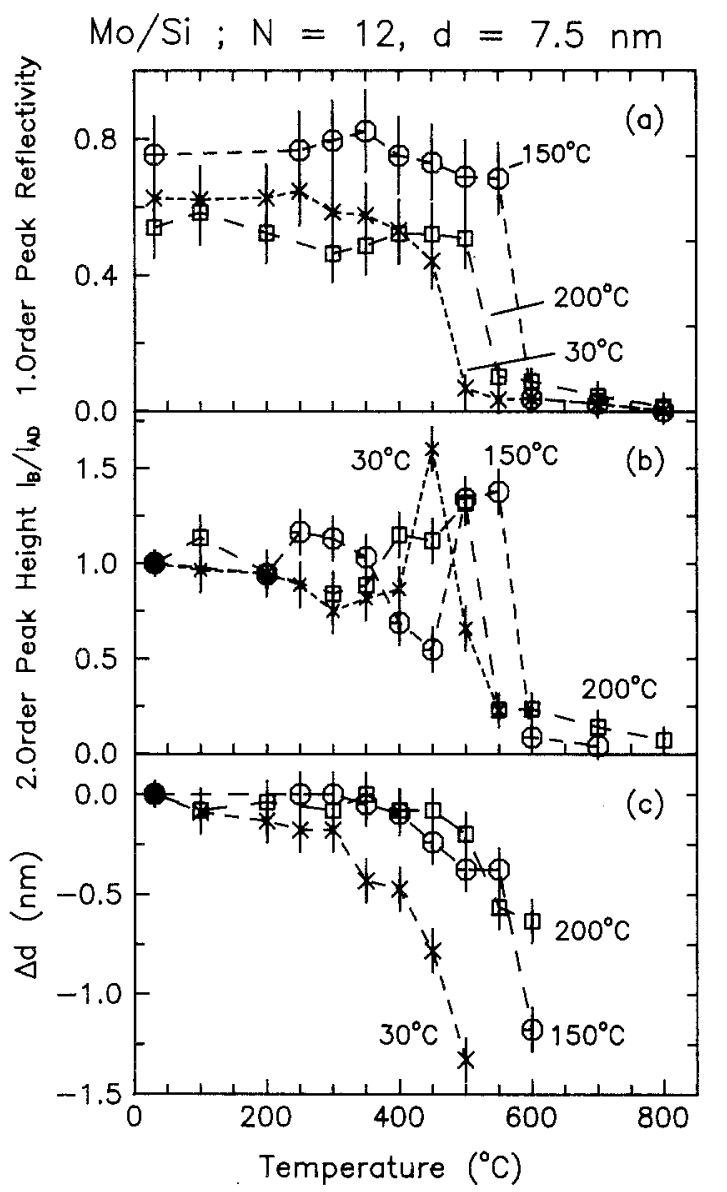

Fig. 3. a First-order Bragg peak reflectivity measured at $\lambda=0.154 \mathrm{~nm}$ versus baking temperature for the mirrors deposited at $30^{\circ} \mathrm{C}$ (crosses), $150^{\circ} \mathrm{C}$ (open circles), $200^{\circ} \mathrm{C}$ (open squares). b Second-order Bragg peak height versus baking temperature for the same $e^{-}$-beam deposited multilayers as in a. The peak heights $\left(I_{\mathrm{T}}\right)$ are normalized to the values of the As Deposited $\left(I_{\mathrm{AD}}\right)$ mirrors. c $\Delta d$ deduced from the angular positions of the third-order Bragg maxima versus baking temperature for the same $e^{-}$-beam deposited samples as in (a) and (b) samples deposited at room temperature, $150^{\circ} \mathrm{C}$ and $200^{\circ} \mathrm{C}$, around $450^{\circ} \mathrm{C}, 550^{\circ} \mathrm{C}$ and $500^{\circ} \mathrm{C}$, respectively.

Figure $3 \mathrm{~b}, \mathrm{c}$ gives a hint on the mechanism that produces the different stability of the samples deposited at different temperatures. The second-order Bragg peak intensities relative to the intensity of the as deposited mirrors for the three $e^{-}$-beam deposited samples versus baking temperature are given in Fig. 3b. For all samples the intensity remains constant at temperatures below $300^{\circ} \mathrm{C}$. Intensity changes are observed around $400^{\circ} \mathrm{C}$ and for all samples the intensity increases considerably at a baking temperature directly below the temperature at which the intensity of the first-order Bragg peak breaks down (see Fig. 3a). The changes of $d$ spacing $(\Delta d)$ of the different stacks versus baking temperature are given in Fig. 3c. They are deduced from the angular positions of the third-order Bragg maxima using a program that corrects for the refraction index of the multilayers. No changes are observed for baking temperatures below $300^{\circ} \mathrm{C}$. At higher baking temperatures significant changes in $\Delta d$ are observed for all samples, but the baking temperatures at which the most significant changes in $\Delta d$ occur are identical with those at which the reflectivities of the first-order Bragg maxima break down (Fig. 3a).

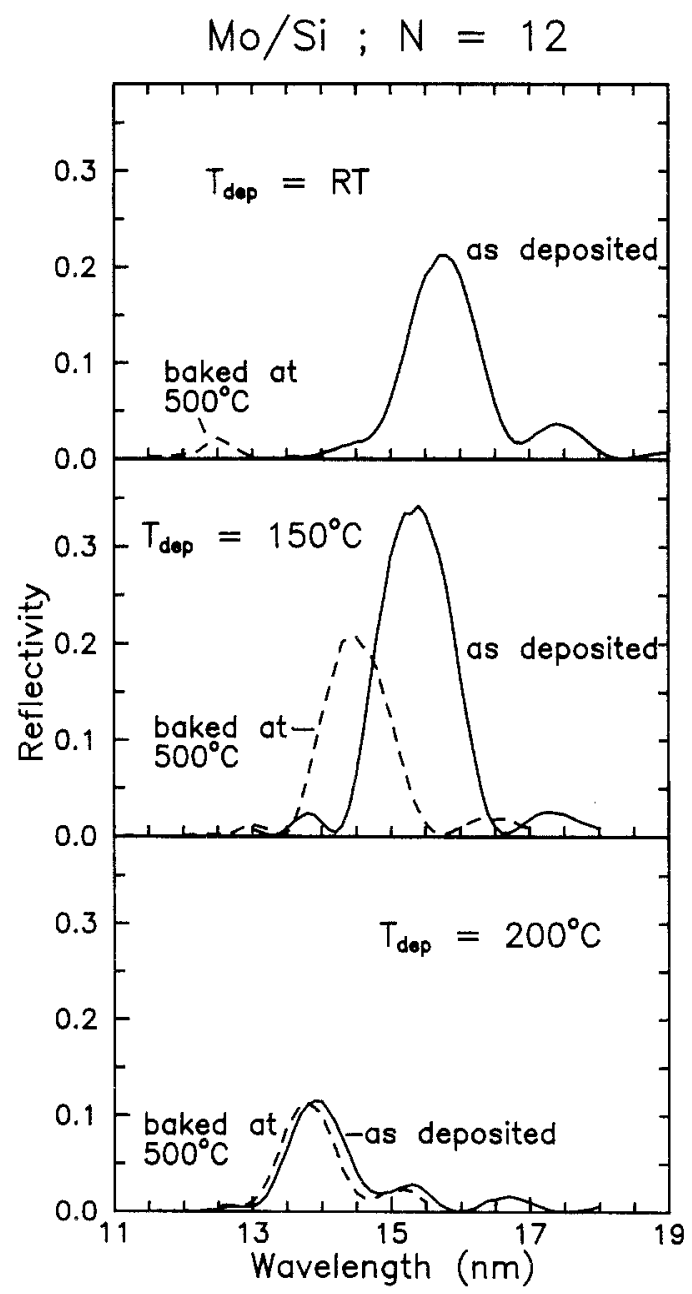

Fig. 4. Normal-incidence soft-X-ray reflectivities versus wavelength of the as-deposited multilayer mirrors (solid curves) and after baking at $500^{\circ} \mathrm{C}$ (dashed curves). The curves in the upper, middle and lower part of the figure were obtained for multilayers deposited at $30^{\circ} \mathrm{C}, 150^{\circ} \mathrm{C}$ and $200^{\circ} \mathrm{C}$, respectively 


\subsection{Reflectivity Measurements with Synchrotron Radiation}

Directly after the deposition and after the $500^{\circ} \mathrm{C}$ baking process the multilayers are characterized with synchrotron radiation in the wavelength range between $11 \mathrm{~nm}$ and $19 \mathrm{~nm}$. Figure 4 shows normal incidence reflectivity curves for the three different multilayers with 12 double layers fabricated at room temperature, $150^{\circ} \mathrm{C}$ and $200^{\circ} \mathrm{C}$. Deposition at $150^{\circ} \mathrm{C}$ yields the highest normal incidence reflectivity of about $35 \%$. The reflectivities in this work are lower than those in $[2,3]$ because the number of double layers $N=12$ is lower than in $[2,3](N=30)$. The reflectivities of the roomtemperature- and the $200^{\circ} \mathrm{C}$-sample are smaller by more than a factor of 2 . After the $500^{\circ} \mathrm{C}$ baking the stack deposited at room temperature is almost completely destroyed. For the multilayer deposited at $150^{\circ} \mathrm{C}$ the reflectivity curve versus wavelength changes in both the maximum intensity and the peak position when baking at $500^{\circ} \mathrm{C}$ is performed but the peak reflectivity is still larger than $20 \%$. For the sample deposited at $200^{\circ} \mathrm{C}$ the $500^{\circ} \mathrm{C}$ baking turns out to have practically no effect on the reflectivity behaviour.

\subsection{High-Resolution RBS}

Additionally, the layer structure of the multilayers was studied for the as-deposited multilayers and after $20 \mathrm{~min}$ baking at $550^{\circ} \mathrm{C}$ and $600^{\circ} \mathrm{C}$ with high-resolution RBS $\left(5 \times 10^{-3}\right)$ [18]. Figure 5 shows the backscattering spectra (intensity measured by the analyser versus backscatter energy) for the sample deposited at $150^{\circ} \mathrm{C}$ obtained with $350 \mathrm{keV} \mathrm{He}^{+}$ions. The spectra in Fig. 5a, b were measured in different scattering geometries. The measuring geometry for (a) was normal ion incidence and an exit angle of $32^{\circ}$. This provides high mass resolution. The spectra in (b) were measured with an incidence angle of $21^{\circ}$ and an exit angle of $77^{\circ}$, both with respect to the surface normal. This results in a good depth resolution. In Fig. 5a the signals of Mo and Si are separated. For the as deposited mirror the signals for both materials show a number of oscillations, which represent the backscattering from the individual layers in the stack. The thickness errors in this layer system are obviously very small $(< \pm 10 \%)$. After baking for $20 \mathrm{~min}$ at $550^{\circ} \mathrm{C}$ the deepness of oscillations in the spectrum is slightly reduced. At a baking temperature of $600^{\circ} \mathrm{C}$ the oscillations have almost vanished. A shift to higher energies is observed for the high-energy edge of the Mo part of the spectrum. These two facts are compatible with an interdiffusion of the Mo and Si layers. The total amount of material does neither change for Mo nor for Si with increasing baking temperature. Therefore, it can be concluded that the change of $d$-spacing with baking (Fig. 3b) is exclusively due to a higher atomic concentration of the materials within the stack. A measurement with an enhanced depth resolution gives hints of the formation of Mo-Si interlayers (Fig. 5b). The spectra in Fig. 5 b shows the backscattering from the uppermost two Mo layers for the as deposited sample and after baking at $550^{\circ} \mathrm{C}$ and $600^{\circ} \mathrm{C}$ measured in a scattering geometry which provides good depth resolution. The shape of the Mo peaks is asymmetric. The slope of the Si- on- Mo (right) side of a Mo peak is higher than the slope of the Moon- Si (left) side. This is a further hint that at the Mo- on- Si interfaces larger $\mathrm{Mo} / \mathrm{Si}$ interlayers exist than at the $\mathrm{Si}$ - onMo interfaces, if the multilayer was thermally treated during deposition $[14,15]$. The slope on the low energy side of the first Mo peak below the surface (Mo- on Si- interface) exhibits a slight shoulder located in the upper region of the decrease. By simulating the RBS spectrum for a given layer system (shown by the dashed curve in Fig. 5b) this shoulder
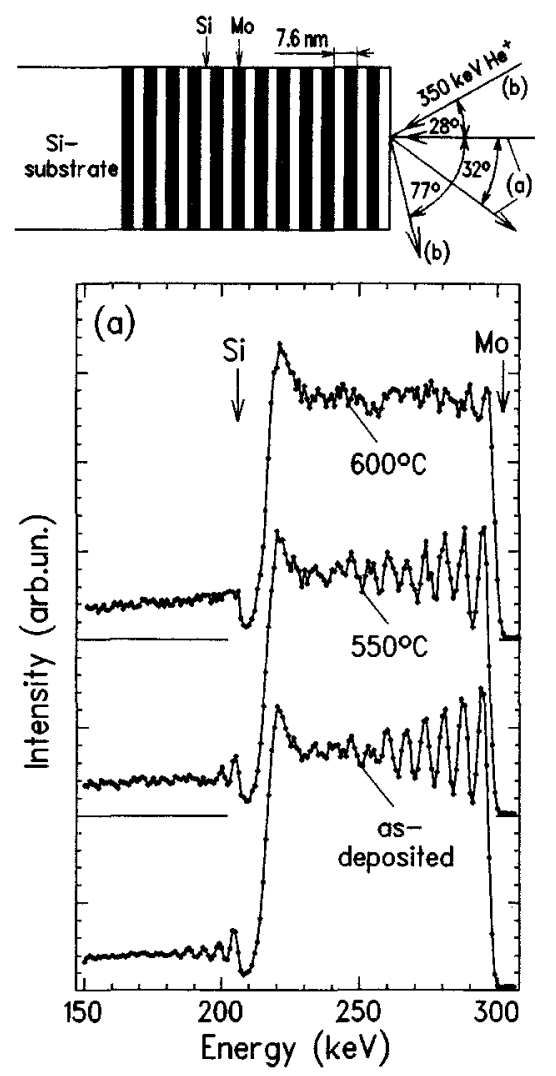

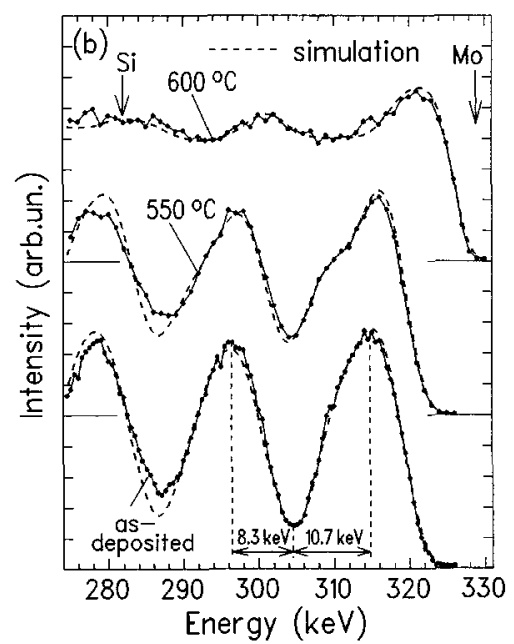

Fig. 5a, b. Rutherford backscattering spectra obtained with an electrostatic analyzer for the multilayer deposited at $150^{\circ} \mathrm{C}$ and after baking at different temperatures. a Geometry which provides good mass resolution; b geometry which provides good depth resolution. The dashed curves in (b) presents simulations of the RBS spectra for a given layer system. The arrows in (a) and (b) indicate the expected energetic positions for ions backscattered from $\mathrm{Si}$ or Mo at the surface 
can only be produced by use of a Mo-rich mixed interlayer at the Mo- on Si- interface. After baking at $550^{\circ} \mathrm{C}$ the deepness of the Mo oscillations is clearly reduced. The major change compared to the as-deposited sample has occurred at the Moon Si-interface, whereas no change in the spectrum at the high-energy side of the first Mo peak (Si- on Mo-interface) is detectable. Therefore, the interdiffusion starts mainly at the Mo- on Si-interface. At this interface a larger shoulder has developed. This shows that the thickness of the interlayer has increased considerably with baking. A simulation of the spectrum after baking at $550^{\circ} \mathrm{C}$ yields a $\mathrm{Si} / \mathrm{Mo}$ atomic ratio in the interlayer close to one. After baking at $600^{\circ} \mathrm{C}$ the oscillations have almost vanished, showing that strong interdiffusion has occurred. Only slightly Mo-richer regions exist in the sample, which might be the residue of the originally pure Mo layers. The simulation of this spectrum yields a $\mathrm{Si} / \mathrm{Mo}$ atomic ratio about 1.7 for the Si-rich regions.

\section{Discussion}

In order to explain the different thermal stability of the three samples, which were fabricated at $30^{\circ} \mathrm{C}, 150^{\circ} \mathrm{C}$ and $200^{\circ} \mathrm{C}$, we must consider the different microstructure of the multilayers deposited at different temperatures. In [12] it was shown that thermal treatment during deposition yields smoother interfaces than deposition at room temperature. Slaughter et al. [14] and Stearns et al. [15] have obtained two kinds of interlayers of amorphous Mo silicides. The thicknesses of the Mo- on- Si interlayers increase with increasing deposition temperature. The thicknesses of the Sion- Mo interlayers remain constant for deposition temperatures between $30^{\circ} \mathrm{C}$ and $300^{\circ} \mathrm{C}$. In consideration of this the data presented in Figs. 1-5 are compatible with the following model.

Deposition at room temperature produces multilayers with a large interface roughness due to a suppression of surface diffusion. Thermal treatment to $150^{\circ} \mathrm{C}$ during deposition yields an enhanced surface diffusion $[14,15]$, smoother interfaces [12] and thicker interlayers of Mo silicides, which were observed with sputter/AES and RBS measurements in agreement with $[14,15]$. In these stacks the concentration gradient for $\mathrm{Si}$ is smaller than for the multilayers deposited at room temperature. The reflectivity of the stacks is then the highest and the films have a higher stability than room temperature deposited films. Deposition at $200^{\circ} \mathrm{C}$ yields broader interlayers and $d$-spacing errors in the stack (this was concluded from the fact that deposition at $200^{\circ} \mathrm{C}$ yields considerably broader Bragg peaks in the $\mathrm{Cu}_{K_{\alpha}}$ reflectivity), which may result from variations of the interface diffusion of Mo and $\mathrm{Si}$ within the stack. Thus the reffectivity is lower, but the stability of this stack is higher.

In Table 1 we compare the thermal stability of our mirrors deposited by $e^{-}$-beam evaporation with the thermal stability of multilayers, which were fabricated by sputtering. The temperature at which the reflectivity of the first order Bragg peaks break down for these mirrors are lower than the baking temperature for our mirrors, which were $e^{-}$-beam deposited and thermally treated during deposition. In the literature activation energies $E_{\mathrm{a}}$ for diffusion were deduced by means of an Arrheniusplot of the multilayer $d$-spacing $\ln (\Delta d)^{2}$ versus 1 /baking temperature $[6,10,11]$. The RBS spectra in Fig. $5 \mathrm{~b}$ show, that for our multilayers the composition of the interlayers changes during baking. In consideration of this an Arrheniusplot on the basis of $\mathrm{Cu}_{K_{\alpha}}$-reflectivity data, which implies a constant ratio of $\mathrm{Si}$ to Mo in the interlayers with baking, is not applicable, because the change in $d$-spacing is no longer proportional to the amount of the diffused material.

\section{Conclusion}

We have studied the thermal stability of Mo/Si multilayers which are produced by $e^{-}$-beam evaporation in UHV and thermal treatment during deposition. In addition to the earlier finding [12] that thermal treatment during deposition can yield a significant increase in the reflectivity of the multilayer this work shows that thermal treatment during deposition has also a considerable effect on the stability of the multilayer. Those multilayers which are produced at the highest deposition temperature, i.e. at $200^{\circ} \mathrm{C}$ in this work, have only a comparatively low peak reflectivity of about $12 \%$ with 12 double layers, which is the half of the

Table 1. Mo/Si multilayer stability for sputtering (data from literature) and $e^{-}$-beam deposition (this study). The table list values of the maximum baking temperature $T_{\max }$ at which the reflectivity of the first-order Bragg peak for $\mathrm{Cu}_{K_{\alpha}}$ radiation (Rosen et al. give only values for soft $\mathrm{X}$-ray radiation) remains larger than 0.2 of the reflectivity of the as deposited sample

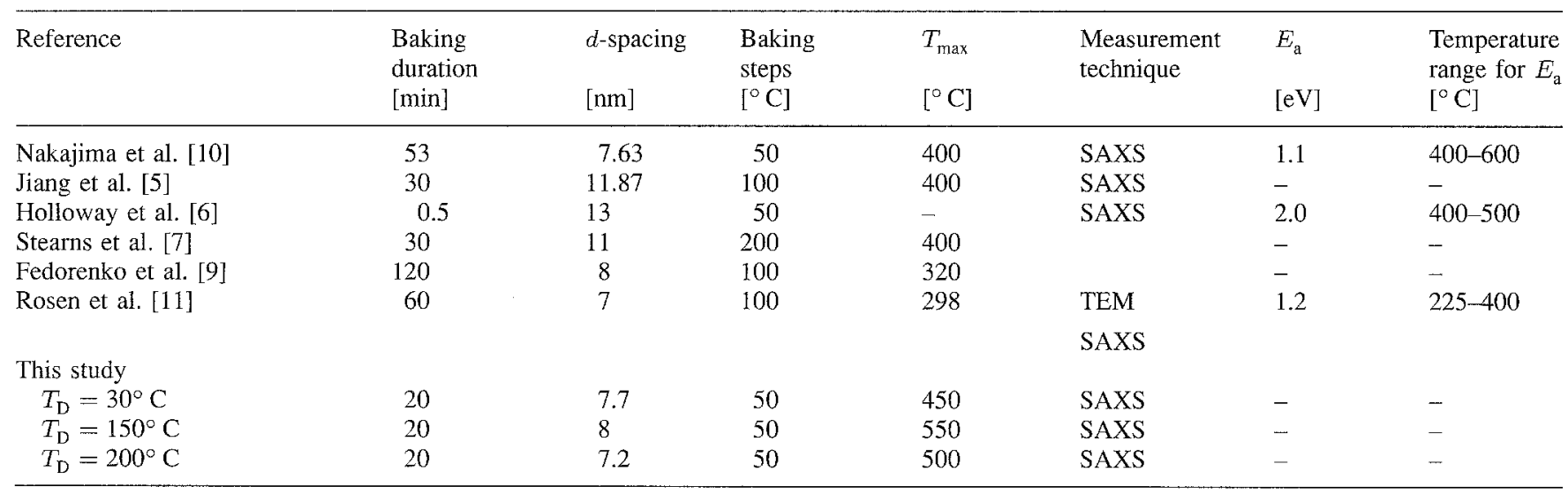


multilayers deposited at $150^{\circ} \mathrm{C}$, but they are showing the best stability.

Acknowledgements. Financial support by BMFT (13N 5994 A) and Fa. Carl Zeiss Oberkochen is gratefully acknowledged. Further we gratefully acknowledge the fruitful cooperation with Dr. Mai and coworkers (IWS, FHG, Dresden).

\section{References}

1. D.P. Gaines, N.M. Ceglio, S.P. Vernon, M. Krumrey, P. Müller: SPIE Proc. 1547, 228 (1991)

2. H.-J. Stock, U. Kleineberg, A. Kloidt, B. Schmiedeskamp, U. Heinzmann, M. Krumrey, P. Müller, F. Scholze: Appl. Phys. Lett. 63, 2207 (1993)

3. B. Schmiedeskamp, A. Kloidt, H.-.J. Stock, U. Kleineberg, T. Döhring, M. Pröpper, S. Rahn, K. Hilgers, B. Heidemann, T. Tappe, U. Heinzmann, M. Krumrey, P. Müller, F. Scholze, K.F. Heidemann: Opt. Eng. 33 (1994) in press

4. R.Z. Bachrach, R.D. Bringaus, N. Hower, I. Lindau, B.B. Pate, P. Pianetta, L.E. Schwartz, R. Tatchyn: SPIE Proc. 447, 10 (1983)

5. Z. Jiang, X. Jiang, W. Liu, Z. Wu: J. Appl. Phys. 65, 196 (1989)

6. K. Holloway, K. Ba Do, R. Sinclair: J. Appl. Phys. 65, 474 (1989)

7. D.G. Stearns, M.B. Stearns, J.H. Stith, Y. Cheng, N.M. Ceglio: J. Appl. Phys. 67, 2415 (1990)
8. P. Boher, Ph. Houdy, L. Hennet, M. Kühne, P. Müller, J.P. Frontier, P. Trouslard, C. Senillou, J.C. Joud, P. Ruterana: SPIE Proc. 1547, 21 (1991)

9. A.I. Fedorenko, S.D. Fanchenko, V.V. Kondratenko, Yu.P. Pershin, A.G. Ponomarenko, E.N. Zubarev, S.A. Yulin: SRI Handbook of Abstracts C7 (1991)

10. H. Nakajima, H. Fujimori, M. Koiwa: J. Appl. Phys. 63, 1046 (1988)

11. R.S. Rosen, M.A. Viliardos, M.E. Kassner, D.G. Stearns, S.P. Vernon: SPIE Proc. 1547, 212 (1991)

12. A. Kloidt, K. Nolting, U. Kleineberg, B. Schmiedeskamp, U. Heinzmann, P. Müller, M. Kühne: Appl. Phys. Lett. 58, 2601 (1991)

13. A. Kloidt, H.-J. Stock, K. Nolting, U. Kleineberg, B. Schmiedeskamp, U. Heinzmann P. Müller, M. Krumrey: TATF 91 Conf. Proc., Les Couches Minces (Suppl.) 259, 173 (1991)

14. J.M. Slaughter, P.A. Kearney, D.W. Schulze, C.M. Falco: SPIE Proc. 134, 73 (1990)

15. M.B. Stearns, C.H. Chang, D.G. Stearns: J. Appl. Phys. 71, 187 (1992)

16. B. Schmiedeskamp, B. Heidemann, U. Kleineberg, A. Kloidt, M.Kühne, P. Müller, K. Nolting, U. Heinzmann: SPIE Proc. 1343, $64(1990)$

17. M. Krumrey, M. Kühne, P. Müller, F. Scholze: SPIE Proc. 1547, $136(1991)$

18. B. Heidemann, T. Tappe, B. Schmiedeskamp, U. Heinzmann: Appl. Surf. Sci. (submitted) 